\title{
Raloxifene (LY139481 HCl) Prevents Bone Loss and Reduces Serum Cholesterol without Causing Uterine Hypertrophy in Ovariectomized Rats
}

\author{
Larry J. Black, Masahiko Sato, Ellen R. Rowley, David E. Magee, Aster Bekele, Daniel C. Williams, George J. Cullinan, \\ Raymond Bendele, ${ }^{*}$ Raymond F. Kauffman, ${ }^{*}$ William R. Bensch, ${ }^{*}$ Charles A. Frolik, John D. Termine, and Henry U. Bryant \\ Department of Skeletal Disease Research, ${ }^{*}$ Department of Cardiovascular Research. and ${ }^{\ddagger}$ Division of Toxicological Research, \\ Eli Lilly and Co., Indianapolis, Indiana 46285
}

\begin{abstract}
There is a medical need for an agent with the positive effects of estrogen on bone and the cardiovascular system, but without the negative effects on reproductive tissue. Raloxifene ( $\mathrm{LY139481} \mathrm{HCl}$ ) is a benzothiophene derivative that binds to the estrogen receptor and inhibits the effects of estrogen on the uterus. In an ovariectomized (OVX) rat model we investigated the effects of raloxifene on bone loss (induced by estrogen deficiency), serum lipids, and uterine tissue. After oral administration of raloxifene for $5 \mathrm{wk}(0.1-10 \mathrm{mg} / \mathrm{kg}$ per d) to OVX rats, bone mineral density in the distal femur and proximal tibia was significantly greater than that observed in OVX controls ${\left(E_{50}\right.}_{50}$ of $0.03-0.3 \mathrm{mg} / \mathrm{kg}$ ). Serum cholesterol was lower in the raloxifene-treated animals, which had a minimal effective dose of 0.1 $\mathrm{mg} / \mathrm{kg}$ and an approximate oral $\mathrm{ED}_{50}$ of $0.2 \mathrm{mg} / \mathrm{kg}$. The effects of raloxifene on bone and serum cholesterol were comparable to those of a $0.1-\mathrm{mg} / \mathrm{kg}$ per $\mathrm{d}$ oral dose of ethynyl estradiol. Raloxifene diverged dramatically from estrogen in its lack of significant estrogenic effects on uterine tissue. Ethynyl estradiol produced a marked elevation in a number of uterine histologic parameters (e.g., epithelial cell height, stromal eosinophilia). These data suggest that raloxifene has promise as an agent with beneficial bone and cardiovascular effects in the absence of significant uterine effects. (J. Clin. Invest. 1994. 93:63-69.) Key words: antiestrogen • benzothiophene • estrogen • ethynyl estradiol - DEXA
\end{abstract}

\section{Introduction}

Osteoporosis is a generalized loss of bone that results in an increased risk of fracture for 20-25 million people in the United States (1). While one form of osteoporosis is associated with the aging process, a second form with a more rapid rate of bone loss occurs in many women after menopause (2). Estrogen deficiency increases bone turnover, with bone resorption occurring more rapidly than formation, resulting in a net loss of bone mineral density, primarily in the trabecular compartment (2). Postmenopausal women are also at a higher risk for coronary heart disease (3), which has been at least partially attributed to an increase in serum lipids (4). Hormone replace-

Address correspondence to Dr. Henry U. Bryant, Skeletal Diseases Research (044), Lilly Corporate Center, Eli Lilly and Co., Indianapolis, IN 56285. 1993

Received for publication 2 April 1993 and in revised form 27 July

J. Clin. Invest.

(C) The American Society for Clinical Investigation, Inc.

0021-9738/94/01/0063/07 \$2.00

Volume 93, January 1994, 63-69 ment is currently considered the optimal therapy, both to protect against bone loss and to reduce the risk of coronary heart disease in postmenopausal women (5). However, there are a number of undesirable effects associated with chronic estrogen therapy that limit the number of patients willing to initiate this treatment and that create difficulties with compliance. These undesirable effects include: resumption of menses, mastodynia, weight gain, and a perceived increased risk for uterine and/or breast cancer $(6,7)$. Thus, an ideal therapy would prevent the bone loss associated with estrogen deficiency and improve the serum lipid profile as estrogen does, without producing significant effects on reproductive tissues.

A number of drugs may offer some protection against postmenopausal bone loss. Calcitonin and the bisphosphonates are antiresorptive agents that attenuate the decline in bone mineral density in postmenopausal women, without noticeable effects on reproductive tissue $(8,9)$. However, no beneficial cardiovascular effects have been attributed to these agents, and other potentially limiting side effects may be associated with calcitonin and bisphosphonates (10). Tamoxifen is an antiestrogen with partial agonist properties that maintains bone mass and lowers serum cholesterol concentrations in postmenopausal women $(11,12)$. However, an estrogen-like uterotrophic type activity of tamoxifen has been documented both in women (13) and in animals (14), thus limiting its use as a prophylactic treatment for postmenopausal osteoporosis.

We have identified an antiestrogen benzothiophene derivative that binds to the estrogen receptor (15), raloxifene (LY139481 HCl; Fig. 1), as a compound that prevents bone loss and lowers serum cholesterol in ovariectomized $(\mathrm{OVX})^{1}$ rats after oral administration, without producing significant uterotrophic activity. The OVX rat is a widely used osteopenic animal model that mimics the development of estrogen deficiency-induced osteopenia in humans. Trabecular bone loss in the OVX rat can be discerned within 4-6 wk after ovariectomy (16). Drugs known to protect against bone loss in postmenopausal women are also effective in the OVX rat, including: estrogen (17), calcitonin (18), bisphosphonates (19), and tamoxifen (20). The OVX rat is also a useful model to detect the hypolipidemic effects of estrogen or tamoxifen $(21,22)$. In this report, the actions of raloxifene are compared with those of ethynyl estradiol on a battery of bone, serum, and uterine parameters in the OVX rat.

\section{Methods}

Animal protocol. Female, virus antibody-free, virgin, Sprague Dawley rats $(225-250 \mathrm{~g}, 10-11$ wk old) were obtained from Charles River Labs.

1. Abbreviations used in this paper: BMD, bone mineral density; DEXA, dual energy $x$-ray absorptiometry; OVX, ovariectomized. 
(Portage, MI) and group housed on a 12-h light/dark cycle (lights on at $0600 \mathrm{~h}$ ), with room temperature set at $22^{\circ} \mathrm{C}$. The animals were allowed to acclimate for $1 \mathrm{wk}$, with ad lib access to both food (TD89222 diet, $0.5 \%$ calcium and $0.4 \%$ phosphorus; Teklad, Madison, WI) and tap water. Rats were anesthetized using ketamine hydrochloride $(120 \mathrm{mg} /$ $\mathrm{kg}$ ) and xylazine hydrochloride ( $24 \mathrm{mg} / \mathrm{kg}$ ) intramuscularly, and a bilateral ovariectomy was performed via a dorsal midline incision just caudal to the 13th rib. Upon recovery from anesthesia, animals were sorted into experimental groups (intact, OVX, OVX plus ethynyl estradiol, and OVX plus raloxifene, with five to six animals per group, per experiment) and compound administration was initiated. Raloxifene $(0.01-$ $10 \mathrm{mg} / \mathrm{kg})$, ethynyl estradiol $(0.1 \mathrm{mg} / \mathrm{kg})$, or vehicle $(1.5 \%$ carboxymethylcellulose) were given by daily oral gavage in a volume of 0.1 $\mathrm{ml} / 100 \mathrm{~g}$ of body weight.

After $5 \mathrm{wk}$ rats were weighed and killed by carbon dioxide asphyxiation. Uteri were removed, weighed, and fixed in $10 \%$ neutral buffered formalin. The left femur and tibia from each animal was removed and frozen for subsequent single photon or dual energy $x$-ray absorptiometry (DEXA). All animals were fasted overnight before blood collection and death. Body weight was recorded for each animal at the time of ovariectomy and immediately before death. The change in body weight over the 5-wk test period was then calculated for each animal. The data presented here have been compiled from seven different experiments in OVX rats. Animal group numbers for each experimental variable are given in the figure and table legends.

Materials. $17 \alpha$-Ethynyl estradiol was purchased from Sigma Chemical Co. (St. Louis, MO). Raloxifene was synthesized at the Lilly Research Laboratories (Indianapolis, IN) by the method described by Jones et al. (15). The compound was $>98.5 \%$ pure as determined by mass spectrometry and elemental analysis.

Serum assays. Blood samples were allowed to clot at $4^{\circ} \mathrm{C}$ for $2 \mathrm{~h}$ and then centrifuged at $2,000 \mathrm{~g}$ for $10 \mathrm{~min}$. Serum samples were aliquoted and stored at $-70^{\circ} \mathrm{C}$ for subsequent analytical procedures. Serum cholesterol was determined using a high performance cholesterol colorimetric assay (Boehringer Mannheim Biochemicals, Indianapolis, IN) (23). Serum triglyceride was determined enzymatically, using a modification of the method described by Bucolo and David (24) with a diagnostics kit (Sigma Chemical Co.). Serum alkaline phosphatase was measured by the paranitrophenylphosphate procedure; phosphorus was measured by the phosphomolybdate procedure on a Monarch chemistry system (761; Instrumentation Laboratory Inc., Lexington, MA); calcium was determined on samples diluted (1:50) in $10 \%$ lanthanum chloride by atomic absorption spectrophotometry using a flame photometer (2100; Perkin-Elmer Corp., Norwalk, CT).

Bone assays. Bone mineral density (BMD) was determined for the distal metaphysis of excised femurs by single photon absorptiometry with a digital bone densitometer (2780; Norland Prods. Inc., N. Brunswick, NJ). Before analysis, the femurs were randomized and then read by an operator who was blinded to the treatment groups. Three transverse scans of $1-\mathrm{mm}$ width were made $6-7 \mathrm{~mm}$ proximal to the distal end of the femur, and the mean of the three repetitions was recorded (25). The BMDs of the excised tibiae were determined by DEXA (Hologic QDR; 1,000 W) using the micro-scan mode $(0.125 \times 0.25-\mathrm{mm}$ pixels) with a line spacing of $0.0254 \mathrm{~cm}$ and a point resolution of $0.0127 \mathrm{~cm}$. BMDs were calculated from the bone mineral content and projected area of longitudinally oriented tibiae as measured from the proximal end to one-half the distance to the fibula/tibia junction as previously described $(26,27)$. Edges were not manipulated, except to remove the fibula.

Uterine histology. Formalin-fixed uteri were processed for conventional paraffin embedding. Hematoxylin and eosin- or Giemsa-stained sections were assayed using a scoring system to quantitate changes in myometrial thickness, endometrial stromal thickness, endometrial cell height, and endometrial stromal eosinophilic infiltrate. Myometrial and stromal thicknesses as well as the epithelial height were expressed as relative measurements based on calibrations in an ocular micrometer on the microscope. The myometrium and stroma were measured perpendicular to the long side of the luminal oval at $\times 80$, while the

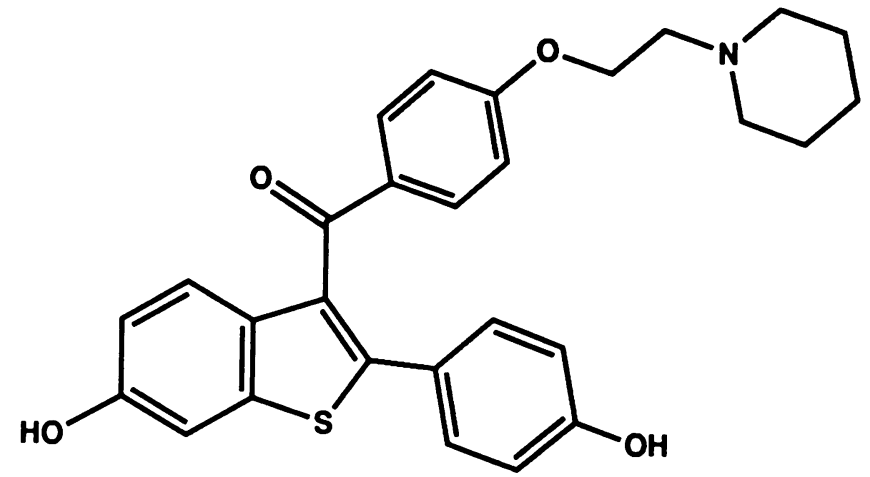

Figure 1. Chemical structure of raloxifene (LY139481 HCl).

epithelial height was measured at $\times 320$. The degree of eosinophilic infiltration was scored on a scale of 1-6, with 1 , absence of eosinophils; and 6, extensive eosinophilia. The scoring was done on the tissue sections chosen randomly within a given study so that the pathologist was blinded to the treatment groups. Raw data were independently analyzed by each individual scoring parameter and as a total of the four parameters combined; this number was termed the total estrogenicity score. The scales were validated using a second, and separate, quantitative analysis of uterine epithelial cell height with a double blind protocol and using a BioQuant System IV automated image analysis system (R\&M Biometrics, Inc., Memphis, TN).

Statistics. Statistical evaluations of the effects of raloxifene or ethynyl estradiol on the various parameters that were measured were made by one-way analysis of variance (ANOVA) with posthoc Scheffe analysis when indicated. Significance was ascribed at $P \leq 0.05$.

\section{Results}

\section{OVX rat studies}

Bone. The effects of raloxifene or ethynyl estradiol on BMD at the distal metaphysis of the femur as measured by single photon absorptiometry are shown in Fig. 2. BMD at this site was $23 \%$ lower in the OVX control rats than in the intact group $(P$ $\leq 0.05$ ). Rats given raloxifene at doses of $0.1-10 \mathrm{mg} / \mathrm{kg}$, had $88-90 \%$ of the BMD observed in intact rats, and were significantly higher than untreated OVX rats $(P \leq 0.05)$. The approximate $\mathrm{ED}_{50}$ by single photon analysis for raloxifene was 0.03 $\mathrm{mg} / \mathrm{kg}$. BMD of the proximal femur in rats given ethynyl estradiol $(0.1 \mathrm{mg} / \mathrm{kg})$ was $93 \%$ of that observed in the intact controls, and was significantly higher than that observed for the untreated OVX rats $(P \leq 0.05)$. This effect of ethynyl estradiol was not statistically different from the raloxifene effect at the $0.1-, 1-$, or $10-\mathrm{mg} / \mathrm{kg}$ doses. Mean BMDs in the estrogen group, and all of the raloxifene groups were less $(P \leq 0.05)$ than that observed in the intact control group.

The proximal tibiae from a separate group of raloxifene and ethynyl estradiol-treated OVX rats were independently analyzed for BMD by DEXA. As shown in Fig. 3, BMD of the proximal tibia was $11 \%$ lower in the OVX control rats as compared with the intact group $(P \leq 0.05)$. Rats treated with raloxifene at doses of 1 and $10 \mathrm{mg} / \mathrm{kg}$ had 98 and $96 \%$, respectively, of the BMD observed in the intact controls, and were significantly higher than untreated OVX rats. The approximated $\mathrm{ED}_{50}$ value from this data was $0.3 \mathrm{mg} / \mathrm{kg}$. The $1-$ and $10-\mathrm{mg} / \mathrm{kg}$ doses of raloxifene were statistically indistinguishable from the intact control group. Mean BMD at the proximal tibia in OVX rats treated with ethynyl estradiol $(0.1 \mathrm{mg} / \mathrm{kg})$ was higher than the OVX control, but not significantly so. 


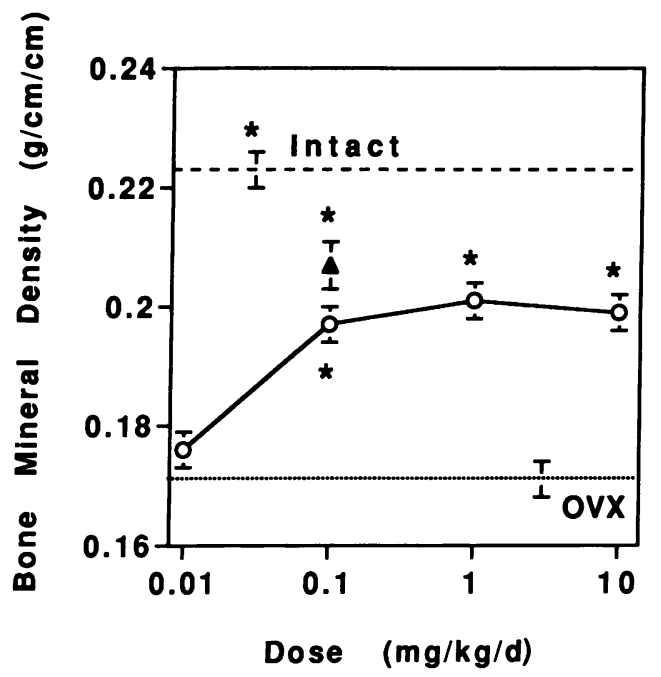

Figure 2. Effect of raloxifene on bone mineral density at the distal metaphysis of the femur in OVX rats as detected by single photon absorptiometry. Each point represents the mean BMD $( \pm$ SEM) combined from six separate experiments for intact controls (dashed line; $n=28)$, OVX control (dotted line; $n=29)$, raloxifene groups $(O-O$; $\mathrm{n}=30$ for each dose level), and ethynyl estradiol $(0.1 \mathrm{mg} / \mathrm{kg}$; group; $\Delta ; n=12$ ). ANOVA of the mean BMD indicated that there was a significant main effect $(\mathrm{F}[6,182]=31.66 ; P=0.0001)$, asterisks indicate groups significantly distinct from the OVX control at $P \leq 0.05$.

Serum lipids. The hypocholesterolemic effect of raloxifene in OVX rats treated for $5 \mathrm{wk}$ is depicted in Fig. 4. The minimally effective hypocholesterolemic dose of raloxifene was 0.1 $\mathrm{mg} / \mathrm{kg}$ (mean serum cholesterol $37 \%$ lower than OVX control; $P \leq 0.05$ ). Maximal lowering of cholesterol (67\% relative to the OVX control; $P \leq 0.05$ ) occurred at $10 \mathrm{mg} / \mathrm{kg}$. The $\mathrm{ED}_{50}$ for cholesterol reduction over this dosage range was $0.2 \mathrm{mg} / \mathrm{kg}$. Ethynyl estradiol at $0.1 \mathrm{mg} / \mathrm{kg}$ also lowered serum cholesterol

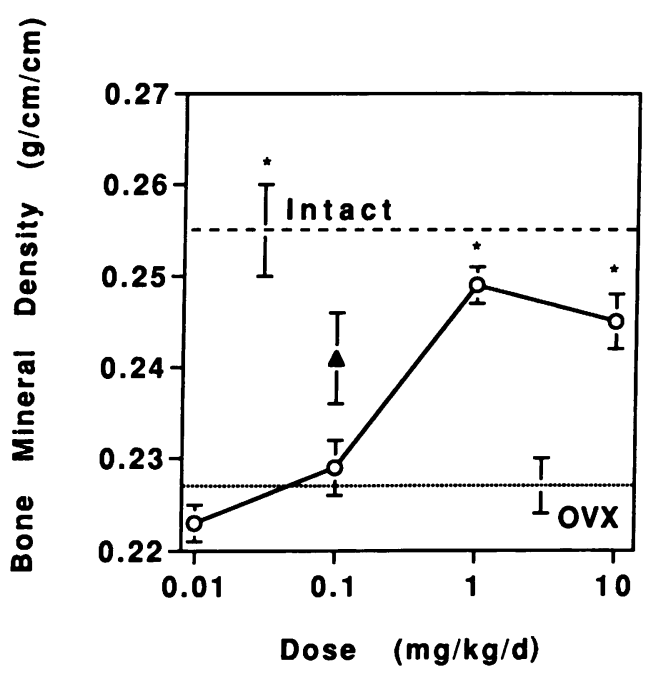

Figure 3. Effect of raloxifene on BMD at the proximal metaphysis of the tibia in OVX rats as detected by dual $\mathrm{x}$-ray absorptiometry. Each point represents the mean $\mathrm{BMD}( \pm \mathrm{SEM})$ for intact controls (dashed line; $n=5$ ), OVX control (dotted line; $n=5$ ), raloxifene groups $(\mathrm{O}-\mathrm{O} ; \mathrm{n}=10-12)$, and ethynyl estradiol $(0.1 \mathrm{mg} / \mathrm{kg} ;$ group $; \mathbf{\Delta} ; \mathrm{n}=$ 6). ANOVA of the mean BMD indicated that there was a significant main effect $(\mathrm{F}[6,53]=15.98 ; P=0.0001)$; asterisks indicate groups significantly distinct from the OVX control at $P \leq 0.05$.

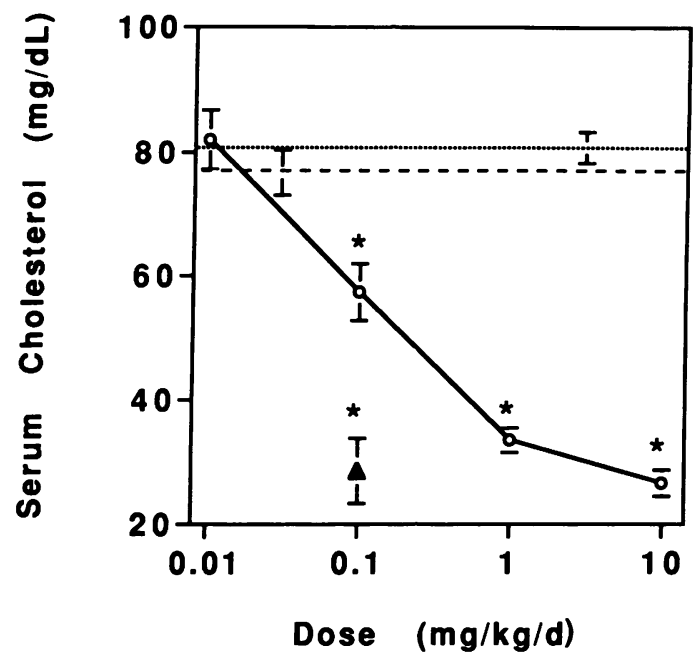

Figure 4. Effect of raloxifene on serum cholesterol levels in OVX rats. Each point represents the mean serum cholesterol $( \pm$ SEM) for intact controls (dashed line; $n=6$ ), OVX control (dotted line; $n=6$ ), raloxifene groups $(O-O ; \mathrm{n}=12)$, and ethynyl estradiol $(0.1 \mathrm{mg} / \mathrm{kg}$; group; $\mathbf{\Delta} ; \mathrm{n}=6$ ). ANOVA of the mean serum cholesterol indicated that there was a significant main effect $(\mathrm{F}[6,59]=41.83 ; P=0.0001)$, asterisks indicate groups significantly distinct from the OVX control at $P \leq 0.05$.

(65\% reduction vs. OVX control; $P \leq 0.05$ ). No significant changes in serum triglyceride concentrations were observed with raloxifene or ethynyl estradiol when compared to OVX controls (Table I).

Uterus. The effects of raloxifene on the uterus in OVX rats are presented in Table II and Fig. 5. As expected, uterine wet weight of the OVX rats was markedly lower than that of the intact controls $(P \leq 0.05)$. Uterine wet weight in rats given $0.1-10 \mathrm{mg} / \mathrm{kg}$ raloxifene was slightly higher $(P \leq 0.05)$ than that of the OVX rats, and was $35-39 \%$ of the uterine weight of the intact controls. At the doses used, the effect of raloxifene on uterine wet weight was not dose related. Ethynyl estradiol at 0.1 $\mathrm{mg} / \mathrm{kg}$ produced substantially heavier uteri than were observed in the OVX group $(P \leq 0.05)$ and which were $91 \%$ of the weight of intact uteri.

The effects of raloxifene, compared with ethynyl estradiol, on uterine histologic parameters are also presented in Table II. Uterine epithelial cell height was nearly $59 \%$ lower in the OVX rats as compared with the intact controls $(P \leq 0.05)$. Raloxifene had no statistically significant effects on uterine epithelial cell height. Ethynyl estradiol, however, produced epithelial cells that were $31 \%$ higher than those measured in intact rats, and that were significantly higher than untreated OVX rats as well $(P \leq 0.05)$. Uterine sections obtained from the intact (Fig. $5 B$ ) and estrogen-treated (Fig. $5 D$ ) rats show epithelial lining cells with typical elongated cell bodies and elongated, diffuse nuclei. Epithelia from OVX rats (Fig. $5 \mathrm{~A}$ ) were more cuboidal in appearance, with smaller, darker staining nuclei. Epithelial cells from raloxifene-treated rats displayed the more cuboidal morphology with the denser, smaller nuclei (Fig. $5 \mathrm{C}$ ). Analysis of uterine epithelial cell height by an automated image analysis technique revealed a similar profile of activity (e.g., higher epithelial cell height with ethynyl estradiol, with no significant difference with raloxifene over the $0.1-3-\mathrm{mg} / \mathrm{kg}$ dosage range; data not shown). 


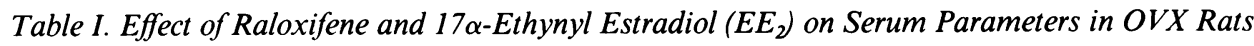

\begin{tabular}{|c|c|c|c|c|c|}
\hline Group & Body weight change* & Triglyceride $^{\ddagger}$ & Calcium $^{\ddagger}$ & Alkaline phosphatase $e^{\ddagger}$ & Phophorus $^{\ddagger}$ \\
\hline & $g$ & $m g / d l$ & $m g / d l$ & IU/liter & $m g / d l$ \\
\hline Intact control & $77.4 \pm 3.1^{\S}$ & $93.8 \pm 16.5$ & $11.6 \pm 0.4$ & $44.8 \pm 5.5$ & $5.7 \pm 0.2$ \\
\hline OVX control & $120.3 \pm 3.8$ & $58.7 \pm 5.1$ & $11.2 \pm 0.6$ & $59.5 \pm 5.2$ & $6.4 \pm 0.3$ \\
\hline $\mathrm{OVX}+\mathrm{EE}_{2}(0.1 \mathrm{mg} / \mathrm{kg})$ & $18.0 \pm 4.0^{\S}$ & $40.7 \pm 4.3$ & $10.6 \pm 0.8$ & $62.5 \pm 6.4$ & $7.1 \pm 0.4$ \\
\hline OVX + raloxifene $(0.01 \mathrm{mg} / \mathrm{kg})$ & $108.6 \pm 4.0$ & $59.1 \pm 6.3$ & $11.2 \pm 0.7$ & $57.2 \pm 3.7$ & $7.2 \pm 0.4$ \\
\hline OVX + raloxifene $(0.1 \mathrm{mg} / \mathrm{kg})$ & $70.5 \pm 3.7^{\S}$ & $50.3 \pm 3.2$ & $10.8 \pm 0.5$ & $66.8 \pm 6.0$ & $7.0 \pm 0.4$ \\
\hline OVX + raloxifene $(1 \mathrm{mg} / \mathrm{kg})$ & $62.2 \pm 3.0^{\S}$ & $60.0 \pm 18.6$ & $10.1 \pm 0.5$ & $69.1 \pm 7.0$ & $7.4 \pm 0.3$ \\
\hline OVX + raloxifene $(10 \mathrm{mg} / \mathrm{kg})$ & $53.7 \pm 2.8^{\S}$ & $41.5 \pm 4.3$ & $11.1 \pm 0.6$ & $68.4 \pm 5.7$ & $6.9 \pm 0.4$ \\
\hline
\end{tabular}

${ }^{*}$ Mean body weight change \pm SEM for 28 (intact control), 29 (OVX control), $12\left(\mathrm{EE}_{2}\right)$, or 30 (each raloxifene dose) rats per group. ${ }^{\ddagger} \mathrm{Mean}$ serum concentrations \pm SEM for $6-12$ rats per group. ${ }^{\S} P \leq 0.05$ vs. OVX control by Scheffe range test.

Uterine myometrial thickness (49\%), stromal expansion (46\%), stromal eosinophilia (78\%), and total estrogenicity (55\%) were all significantly lower in untreated OVX rats, relative to the intact controls (Table II). The mean scores for each of these parameters were slightly higher in the raloxifenetreated animals, but these small differences were not related to dose and were not statistically significant. Each of these parameters were markedly higher in ethynyl estradiol-treated rats as compared with the untreated OVX controls $(P \leq 0.05$; Table II).

Additional measurements. Raloxifene administration for 5 wk was not associated with any overt signs of toxicity. Ovariectomy was associated with a significantly higher body weight as compared with the intact controls $(55 \%$ higher 5 -wk weight gain vs. intact control group; $P \leq 0.05$; Table I). Rats given raloxifene at doses of $0.1-10 \mathrm{mg} / \mathrm{kg}$ had $69-91 \%$ of the body weight gain that was observed in intact controls, and were significantly lower than untreated OVX controls $(P \leq 0.05)$. Estrogen had a dramatic effect on weight gain, as the ethynyl estradiol-treated rats had only $23 \%$ of the weight gain observed in the intact controls and were lower than the OVX controls $(P$ $\leq 0.05$ ). The results of additional serum assays are presented in Table I. No significant differences were observed with ovariectomy or either of the drug treatments on total serum calcium levels, alkaline phosphatase activity, or inorganic phosphorus levels.

\section{Discussion}

These data demonstrate a unique profile of activity for raloxifene in estrogen-deficient animals. Bone loss in the OVX rat parallels the very early skeletal changes observed immediately in postmenopausal women: rapid decrease in bone mass, preferential loss of trabecular bone, and responsiveness to estrogen replacement therapy (28). As in postmenopausal women, estrogen deficiency in the rat produces a high turnover state in trabecular bone where resorption of bone outpaces formation, resulting in net loss of bone mass (28). Increases in both the number of osteoclasts and the percentage of trabecular bone covered by osteoclasts can be observed within $28 \mathrm{~d}$ of ovariectomy in the rat (20). In our hands, ovariectomy resulted in significant osteopenic responses by $5 \mathrm{wk}$ in both the femur and tibia as measured by single photon absorptiometry and DEXA densitometric techniques, respectively. Ethynyl estradiol (an orally bioavailable estrogen) prevented OVX-induced bone loss, consistent with previous reports that used $17 \beta$-estradiol $(17,29)$.

Raloxifene blocked the decline in BMD observed in OVX rats at doses as low as $0.1 \mathrm{mg} / \mathrm{kg}$. The magnitude of this effect of raloxifene was indistinguishable from that of ethynyl estradiol at $0.1 \mathrm{mg} / \mathrm{kg}$. This observation is consistent with a previous report in which raloxifene (previously known as keoxifene) in-

Table II. Effect of Raloxifene and 17 $\alpha$-Ethynyl Estradiol $\left(E E_{2}\right)$ on Uterine Wet Weight and Histologic Parameters in OVX Rats

\begin{tabular}{|c|c|c|c|c|c|c|}
\hline Group & $\begin{array}{l}\text { Uterine } \\
\text { weight* }\end{array}$ & $\begin{array}{l}\text { Uterine } \\
\text { epithelial }^{\text {height }}\end{array}$ & $\begin{array}{c}\text { Uterine } \\
\text { myometrial } \\
\text { thickness }^{\ddagger}\end{array}$ & $\begin{array}{l}\text { Uterine stromal } \\
\text { expansion }^{\ddagger}\end{array}$ & $\begin{array}{l}\text { Uterine stromal } \\
\text { eosinophilia }{ }^{\ddagger}\end{array}$ & $\begin{array}{c}\text { Total } \\
\text { estrogenicity } \\
\text { score }^{t}\end{array}$ \\
\hline & $m g$ & & & & & \\
\hline Intact control & $535 \pm 23^{\S}$ & $2.9 \pm 0.2^{\S}$ & $8.5 \pm 0.2^{\S}$ & $20.0 \pm 0.7^{\S}$ & $4.5 \pm 0.3^{\S}$ & $38.8 \pm 1.2^{\S}$ \\
\hline OVX control & $127 \pm 5$ & $1.2 \pm 0.1$ & $4.3 \pm 0.2$ & $10.7 \pm 0.3$ & $1.0 \pm 0$ & $17.4 \pm 0.5$ \\
\hline $\mathrm{OVX}+\mathrm{EE}_{2}(0.1 \mathrm{mg} / \mathrm{kg})$ & $489 \pm 19^{\S}$ & $3.8 \pm 0.2^{\S}$ & $8.8 \pm 0.3^{\S}$ & $20.0 \pm 0.6^{8}$ & $4.9 \pm 0.2^{\S}$ & $40.4 \pm 1.1^{\S}$ \\
\hline OVX + raloxifene $(0.01 \mathrm{mg} / \mathrm{kg})$ & $150 \pm 4$ & $1.6 \pm 0.1$ & $5.2 \pm 0.2$ & $11.8 \pm 0.5$ & $1.2 \pm 0.2$ & $19.7 \pm 0.9$ \\
\hline OVX + raloxifene $(0.1 \mathrm{mg} / \mathrm{kg})$ & $196 \pm 5^{\S}$ & $1.8 \pm 0.1$ & $5.0 \pm 0.2$ & $13.0 \pm 0.4$ & $1.2 \pm 0.1$ & $21.4 \pm 0.6$ \\
\hline OVX + raloxifene $(0.3 \mathrm{mg} / \mathrm{kg})$ & $209 \pm 19^{\S}$ & $1.4 \pm 0.1$ & $5.1 \pm 0.2$ & $13.2 \pm 0.5$ & $1.0 \pm 0$ & $22.3 \pm 0.7$ \\
\hline OVX + raloxifene $(1 \mathrm{mg} / \mathrm{kg})$ & $199 \pm 5^{\S}$ & $1.7 \pm 0.1$ & $5.0 \pm 0.2$ & $13.0 \pm 0.4$ & $1.1 \pm 0.6$ & $21.1 \pm 0.8$ \\
\hline OVX + raloxifene $(3 \mathrm{mg} / \mathrm{kg})$ & $193 \pm 8^{\S}$ & $1.3 \pm 0.1$ & $4.7 \pm 0.2$ & $13.2 \pm 0.4$ & $1.2 \pm 0.2$ & $21.3 \pm 0.7$ \\
\hline OVX + raloxifene $(10 \mathrm{mg} / \mathrm{kg})$ & $186 \pm 4^{\S}$ & $1.6 \pm 0.1$ & $4.8 \pm 0.2$ & $11.8 \pm 0.4$ & $1.0 \pm 0$ & $18.9 \pm 0.7$ \\
\hline
\end{tabular}

\footnotetext{
${ }^{*}$ Mean uterine wet weight $\pm \mathrm{SEM}$; for 6-12 rats per group. ${ }^{\ddagger}$ Mean histologic score \pm SEM for 6-12 rats per group, measurements ascribed as
} described in Methods. ${ }^{\S} P \leq 0.05$ vs. OVX control by Scheffe range test. 

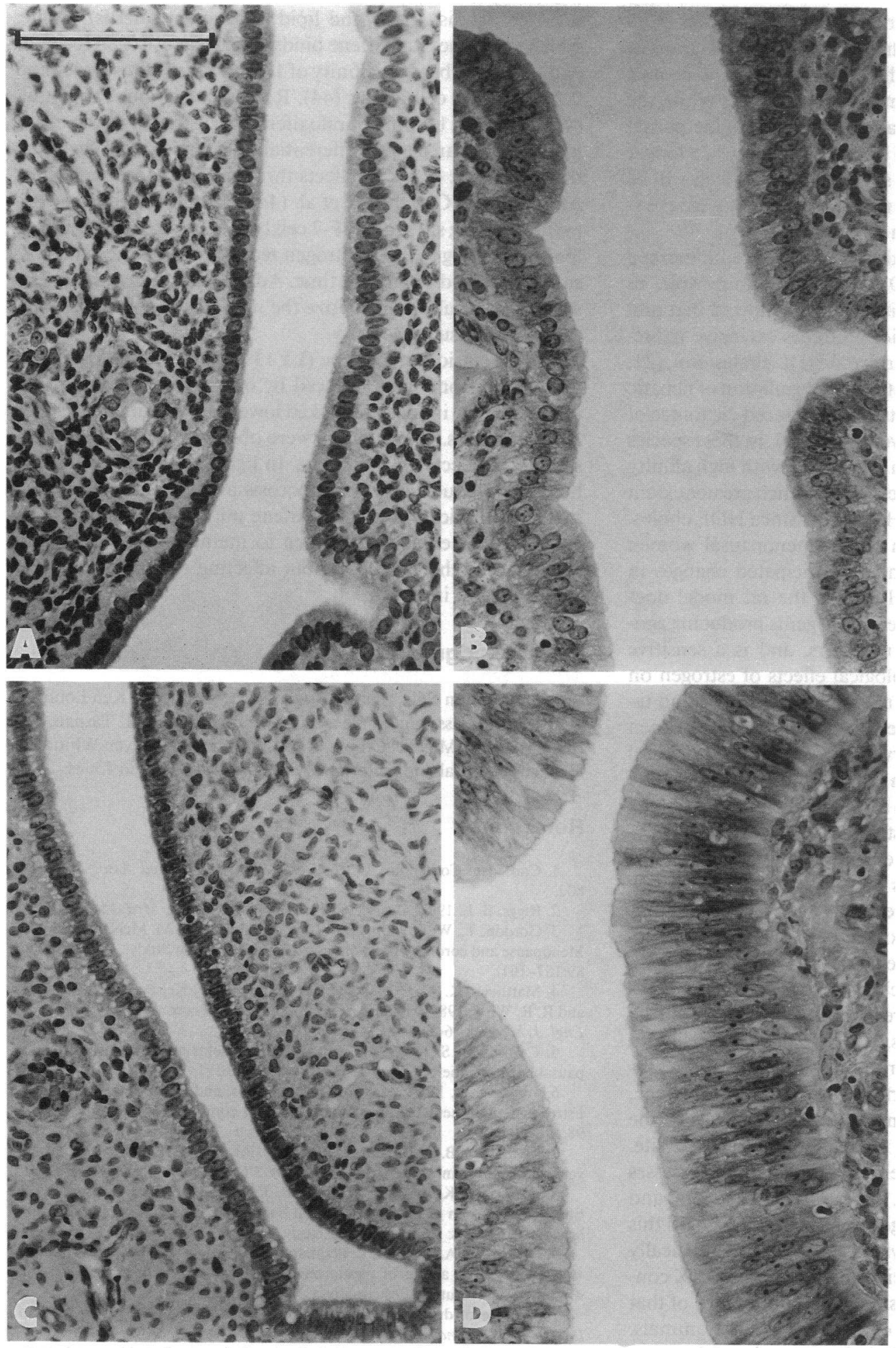

Figure 5. Hemotoxylin and eosin-stained sections of rat uteri, illustrating epithelial lining cells, obtained from ovariectomized controls $(A)$, intact controls $(B)$ and ovariectomized rats treated for $5 \mathrm{wk}$ with raloxifene $(1 \mathrm{mg} /$ $\mathrm{kg} ; C)$ or ethynyl estradiol $(0.1$ $\mathrm{mg} / \mathrm{kg} ; D)$. The marked hypertrophic effect of ethynyl estradiol on uterine epithelial cells is not observed in the uteri obtained from raloxifene-treated rats ( $\times 300$; bar in $A=100 \mu \mathrm{m}$ ).

creased ash weight per unit volume in OVX rats (30). In this age rat, bone elongation rate at the proximal tibial growth cartilage is $\sim 70 \mu / \mathrm{d}(31)$. The new cancellous bone added to the metaphysis during bone elongation can be a confounding factor, particularly when evaluating new classes of agents. It seems likely the mode of action of raloxifene in the OVX rat was, like other antiresorptive agents, to block resorption of metaphyseal trabeculae. However, one cannot formally rule out a stimula- tory effect on the endochondral formation processes in the primary spongiosa, except by experimentation using OVX rats aged $\geq 6$ mo. Recent histomorphometric data show that raloxifene prevented the loss of trabecular bone in the proximal tibia of OVX rats of a similar age and weight (32). Other antiestrogenic compounds, such as tamoxifen (20) and clomifene (33), produce similar effects on bone in OVX rats. While the precise mechanism for antiestrogen effects on bone is unknown, histo- 
morphometric data from Turner et al. (20) and Moon et al. (34) show that tamoxifen and estrogen have similar actions in the diaphysis and metaphysis of the tibia, suggesting an agonist or partial agonist activity for tamoxifen on bone. While the results of this study show that raloxifene will provide partial protection against OVX-induced bone loss after $5 \mathrm{wk}$, a longer term study must be performed to show that these effects will be maintained and that raloxifene is not simply delaying the eventual loss of BMD due to estrogen deficiency.

Raloxifene and ethynyl estradiol both produced a marked hypocholesterolemic effect in OVX rats. Previous work in OVX rats and intact rabbits of either gender showed that oral administration of ethynyl estradiol produces extensive reductions in both total serum cholesterol and HDL cholesterol, (21, $35,36)$. These effects were attributed to upregulation of hepatic LDL receptors by estrogen, resulting in enhanced clearance of circulating LDL $(35,37)$. The lowering of HDL in these species is due to the presence of $\mathrm{ApoE}$, an apoprotein with high affinity for the LDL receptor, which is present to a much greater extent in rat as compared with human HDL (36). Since HDL cholesterol is not reduced by estrogen in postmenopausal women (38), the rat data shed little light on anticipated changes in HDL metabolism in humans. However, the rat model does predict reduction of LDL cholesterol for agents producing agonist effects upon liver estrogen receptors, and is a sensitive model for monitoring pharmacological effects of estrogen on total cholesterol in vivo. To this regard, both estrogen and tamoxifen have been shown to lower LDL cholesterol in women $(5,12)$. Recent clinical observations in postmenopausal women after relatively short term administration of raloxifene ( $2 \mathrm{mo}$ ) indicate a similar effect on serum total cholesterol in the absence of changes in uterine histology (39).

Whereas raloxifene produced effects very similar to those of estrogen and other antiestrogens on bone and serum cholesterol, there is a striking difference in the effects of these compounds on uterine tissue, as raloxifene lacked uterotrophic activity. The pharmacology of antiestrogens, such as tamoxifen, is complex. While "antiestrogenic" in the sense that it: (a) competes with estrogen for estrogen receptors, $(b)$ produces partial uterine atrophy in intact animals, and (c) causes regression in certain estrogen dependent tumors, tamoxifen also displays estrogen agonist-like effects on certain tissues (40). Raloxifene, however, is a more pure antagonist of estrogen effects in the uterus (41), lacking appreciable agonist activity at that site. Thus, raloxifene is a unique agent that apparently possesses sufficient intrinsic activity to act like an agonist in bone and liver, but is a relatively pure antagonist in uterine tissue. In this study, both raloxifene and ethynyl estradiol caused statistically significant increases in uterine weight relative to the OVX controls. This effect of raloxifene was only about one-third of that observed in the intact controls or estrogen-treated animals. This effect may be related to the slight hypertrophy of the myometrium and endometrial stroma, which in previous work has been attributed to water retention $(42,43)$. Raloxifene's minimal stimulatory effect on endometrial epithelium suggests a lower cancer risk compared with chronic administration of estrogen.

The precise mechanism for raloxifene's beneficial effect on bone and lipids in the OVX rat, and for its relative tissue specificity (i.e., lack of agonistic effect on uterine epithelia), remains uncertain. Raloxifene possesses estrogen antagonist properties in the uterus of estrogen-stimulated OVX rats (41), suggesting a mixed agonist (bone and lipid)/antagonist (uterus) profile, which is unique. Raloxifene binds to nuclear estrogen receptor with a relative binding affinity of 1.5 in uterine cytosol (41) and 0.2 in MCF-7 cell lysates (44). Recent data from Yang et al. (45) show that binding of raloxifene and estrogen to the estrogen receptor can lead to differential gene regulation, suggesting that raloxifene exerts its effects through the estrogen receptor. Alternatively, Glasebrook et al. (44) have described other potential binding sites in MCF-7 cell lysates using tritiated raloxifene, indicating that nonestrogen receptor-based mechanisms, cannot be ruled out at this time. Additional studies are underway to more fully characterize the mechanism for raloxifene's action and tissue specificity.

In conclusion, raloxifene (LY139481 $\mathrm{HCl}$ ) attenuated the decrease in bone mass induced by ovariectomy in the rat, at doses that also induced a marked lowering of serum cholesterol concentrations. These effects were observed in the absence of significant effects on the uterus. In light of the serious human health consequences of osteoporosis and coronary heart disease, the implication that raloxifene might offer a useful therapy for postmenopausal women to maintain bone mass and lower serum cholesterol without affecting reproductive tissue merits further investigation.

\section{Acknowledgments}

We thank Harlan Cole, Charles Brown, Peggy Hoge, and Ken Lobb for their technical assistance. We also thank Drs. Armen H. Tasjian, Jr., Janet M. Hock, Michael Draper, Richard Swain, and Steven Whittaker for their technical and editorial advice, and Dr. C. David Jones.

\section{References}

1. Consensus Conference. Osteoporosis. 1984. J. Am. Med. Assoc. 252:799_ 802.

2. Riggs, B. L. 1991. Overview of osteoporosis. West. J. Med. 154:63-77.

3. Gordon, T., W. B. Kannel, M. C. Hjortland, and P. M. McNamara. 1978. Menopause and coronary heart disease: The Framingham Study. Ann. Int. Med. 89:157-161.

4. Matthews, K. A., E. Meilahn, L. H. Kuller, S. F. Kelsey, A. W. Cagguila, and R. R. Wing. 1989. Menopause and risk factors for coronary heart disease. $N$. Engl. J. Med. 321:641-646.

5. Cummings, S. R. 1991. Evaluating the benefits and risks of postmenopausal hormone therapy. Am. J. Med. 91(Suppl. 5B):14S-18S.

6. Judd, H. L., D. R. Meldrum, L. J. Deftos, and B. E. Henderson. 1983 Estrogen replacement therapy: Indications and complications. Ann. Int. Med. 98:195-205.

7. Henderson, B. E., R. K. Ross, and M. C. Pike. 1993. Hormonal chemoprevention of cancer in women. Science (Wash. DC). 259:633-638.

8. Overgaard, K., M. A. Hansen, S. B. Jensen, and C. Christiansen. 1992. Effect of salcatonin given intranasally on bone mass and fracture rates in established osteoporosis: A dose-response study. Br. Med. J. 305:556-561.

9. Fromm, G. A., E. Vega, L. Plantalech, A. M. Galich, and C. A. Mautalen. 1991. Differential action of pamidronate on trabecular and cortical bone in women with involutional osteoporosis. Osteoporosis Int. 1:129-133.

10. Choice of drugs for postmenopausal osteoporosis. 1992. The Medical Letter On Drugs and Therapeutics 34:101-102.

11. Love, R. R., R. B. Mazess, H. S. Barden, S. Epstein, P. A. Newcomb, V. C. Jordan, P. P. Carbone, and D. L. DeMets. 1992. Effects of tamoxifen on bone mineral density in postmenopausal women with breast cancer. $N$. Engl. J. Med. 326:852-856.

12. Love, R. R., D. A. Wiebe, P. A. Newcomb, L. Cameron. H. Leventhal, V. C. Jordan, J. Feyzi, and D. L. DeMets. 1991. Effects of tamoxifen on cardiovascular risk factors in post-menopausal women. Ann. Intern. Med. 115:860-864.

13. Love, R. R., L. Cameron, B. L. Connell, and H. Leventhal. 1991. Symptoms associated with tamoxifen treatment in postmenopausal women. Arch. Intern. Med. 151:1842-1847.

14. Kurl, R. N., and N. M. Borthwick. 1980. Clomiphene and tamoxifen action in the rat uterus. J. Endocrinol. 85:519-524.

15. Jones, C. D., T. Suarez, E. H. Massey, L. J. Black, and F. C. Tinsley. 1979. Synthesis and anti-estrogenic activity of [3,4-dihydro-2-(4-methoxyphenyl)-1- 
napthalenyl] [4-[2-pyrrolidinyl) ethoxy]-phenyl] methanone, methanesulfonic acid salt. J. Med. Chem. 22:962-966.

16. Wronski, T. J., and C.-F. Yen. 1991. The ovariectomized rat as an animal model for postmenopausal bone loss. Cells Mater. (Suppl. 1):69-74.

17. Kalu, D. N., C. C. Liu, E. Salerno, B. Hollis, R. Echon, and M. Ray. 1991 Skeletal response of ovariectomized rats to low and high doses of $17 \beta$-estradiol Bone Miner. 14:175-187.

8. Wronski, T. J., C.-F. Yen, K. W. Burton, R. C. Mehta, P. S. Newman, E. E. Soltis, and P. P. DeLuca. 1991. Skeletal effects of calcitonin in ovariectomized rats. Endocrinology. 129:2246-2250.

19. Seedor, J. G., H. A. Quartuccio, and D. D. Thompson. 1991. The bisphosphonate alendronate (MK-217) inhibits bone loss due to ovariectomy in rats. $J$ Bone Miner. Res. 6:339-346.

20. Turner R. T., G. K. Wakely, K. S. Hannon, and N. H. Bell. 1988. Tamoxifen inhibits osteoclast-mediated resorption of trabecular bone in ovarian hormone-deficient rats. Endocrinology. 122:1146-1150.

21. Staels, B., J. Auwerx, L. Chan, A. von Tol, M. Rosseneu, and G. Verhoeven. 1989. Influence of development, estrogens, and food intake on apolipoprotein A-I, A-II and E mRNA in rat liver and intestine. J. Lipid Res. 30:1137-1145.

22. Donati, R. J., P. V. Harper, A. Hughes, and R. V. Hay. 1990. Serum cholesterol- and apoprotein B-lowering effects of cis-tamoxifen. Arteriosclerosis. 10:822A

23. Wiebe, D. A., and J. T. Bernert. 1984. Influence of incomplete cholesteryl ester hydrolysis on enzymatic measurements of cholesterol. Clin. Chem. 30:352356.

24. Bucolo, G., and H. David. 1973. Quantitative determination of serum triglycerides by the use of enzymes. Clin. Chem. 19:476-482.

25. Roudebush, R. E., D. E. Magee, D. N. Benslay, A. M. Bendele, and H. U. Bryant. 1993. Effect of weight manipulation on bone loss due to ovariectomy and the protective effects of estrogen in the rat. Calcif. Tissue Int. 53:61-64.

26. Ammann, P., R. Rizzoli, D. Slosman, and J. P. Bonjour. 1992. Sequential and precise in vivo measurement of bone mineral density in rats using dual energy x-ray absorptiometry. J. Bone Miner. Res. 7:311-316.

27. Griffen, M. G., R. Kimble, W. Hopfer, and R. Pacifici. 1993. Dual energy $\mathrm{x}$-ray absorptiometry of the rat: Accuracy, precision and measurement of bone loss. J. Bone Miner. Res. 8:795-800.

28. Kalu, D. N. 1991. The ovariectomized rat model of post-menopausal bone loss. Bone Miner. 15:175-192.

29. Wronski, T. J., M. Cintron. A. L. Doherty, and L. M. Dann. 1988. Estrogen treatment prevents osteopenia and depresses bone turnover in ovariectomized rats. Endocrinology. 123:681-686.

30. Jordan, V. C., E. Phelps, and J. U. Lindgren. 1987. Effects of anti-estrogens on bone in castrated and intact female rats. Breast Cancer Res. Treat. 10:31 35 .
31. Turner, R. T., G. L. Evans, and G. K. Wakely. 1993. Mechanism of action of estrogen on cancellous bone balance in tibiae of ovariectomized growing rats: Inhibition of indices of formation and resorption. J. Bone Miner. Res. 8:359-366.

32. Evans, G., H. U. Bryant, M. Sato, and R. T. Turner. 1993. Raloxifene is a tissue specific estrogen agonist. J. Bone Miner. Res. 8(Suppl. 1):S134.

33. Beall, P. T., L. K. Misra, R. L. Young, H. J. Spjut, H. J. Evans, and A. LeBlanc. 1984. Clomiphene protects against osteoporosis in the mature ovariectomized rat. Calcif. Tissue Int. 36:123-125.

34. Moon, L. Y., G. K. Wakely, and R. T. Turner. 1991. Dose-dependent effects of tamoxifen on long bones in growing rats: Influence of ovarian steroids. Endocrinology: 129:1568-1574.

35. Ma P. T. S. T. Yamamoto, J. L. Goldstein, and M. S. Brown. 1986. Increased mRNA for low density lipoprotein receptor in livers of rabbits treated with 17- $\alpha$-ethinyl estradiol. Proc. Natl. Acad. Sci. USA. 83:792-796.

36. Chao. Y.. E. E. Windler, G. C. Chen, and R. J. Havel. 1979. Hepatic catabolism of rat and human lipoproteins in rats treated with 17- $\alpha$-ethinyl estradiol. J. Biol. Chem. 254:11360-11366.

37. Brown. M. S., and J. L. Goldstein. 1980. The estradiol-stimulated lipoprotein receptor of rat liver. J. Biol. Chem. 255:10464-10471.

38. Walsh B. W. I. Schiff. B. Rosner. L. Greenberg, V. Ravnikar, and F. M Sacks. 1991. Effects of post-menopausal estrogen replacement on the concentrations and metabolism of plasma lipoproteins. N. Engl. J. Med. 325:1196-1204.

39. Draper. M. W.. D. E. Flowers. W. J. Huster, and J. A. Nield. 1993. Effects of raloxifene $(\mathrm{LY} 139481 \mathrm{HCl})$ on biochemical markers of bone and lipid metabolism in healthy post-menopausal women. In Proceedings of the Fourth International Symposium on Osteoporosis, Hong Kong. In press.

40. Jordan. V. C. K. E. Allen. and C. J. Dix. 1980. Pharmacology of tamoxifen in laboratory animals. Cancer Treal. Rep. 64:745-759.

41. Black. L. J.. C. D. Jones, and J. F. Falcone. 1983. Antagonism of estrogen action with a new benzothiophene derived antiestrogen. Life Sci. 32:1031-1036.

42. Szego. C., and S. Roberts. 1953. Steroid action and interactions in uterine metabolism. Recent Prog. Horm. Res. 8:419-468.

43. Black, L. J., C. D. Jones. J. H. Clark, and J. A. Clemens. 1982. LY156758 A unique anti-estrogen displaying high affinity for estrogen receptors, negligible estrogenic acitivity and near-total estrogen antagonism in vivo. Breast Cancer Res. Treat. 2:279.

44. Glasebrook. A. L., D. L. Phillips. and J. P. Sluka. 1993. Multiple binding sites for the anti-estrogen raloxifene. J. Bone Miner. Res. 8(Suppl. 1):S268.

45. Yang, N. N.. S. Hardikar, J. Kim, and M. Sato. 1993. Raloxifene, an anti-estrogen, simulates the effects of estrogen on inhibiting bone resorption through regulating TGF $\beta-3$ expression in bone. J. Bone Miner. Res. 8(Suppl. 1):S118. 